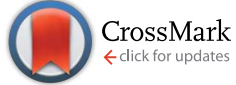

Cite this: RSC Adv., 2015, 5, 38660

Received 13th January 2015 Accepted 22nd April 2015

DOI: $10.1039 / c 5 r a 00764 j$

www.rsc.org/advances

\section{Improving cyclic performance of Si anode for lithium-ion batteries by forming an intermetallic skin $\uparrow$}

\author{
Xingkang Huang, ${ }^{a}$ Shun Mao, ${ }^{a}$ Jingbo Chang, ${ }^{a}$ Peter B. Hallac, ${ }^{b}$ Christopher R. Fell, \\ Yanting Luo, ${ }^{b}$ Bernhard Metz, ${ }^{b}$ Junwei Jiang ${ }^{b}$ and Junhong Chen ${ }^{\star a}$
}

An intermetallic $\mathrm{NiSi}_{x}$ coating layer was introduced on the Si surface by sputtering $\mathrm{Ni}$ onto $\mathrm{Si}$, followed by heat-treatment. The resulting chemically bonded $\mathrm{NiSi}_{x}$ layer, unlike physically coated layers that typically can crack and detach from Si surfaces upon repeated cycling, remains connected with the bulk Si as a skin-like protective surface.

$\mathrm{Si}$, as an anode for lithium-ion batteries, possesses the highest theoretical capacity of $3579 \mathrm{~mA} \mathrm{~h} \mathrm{~g}^{-1}$ at room temperature. ${ }^{1}$ Cyclic performance is one of the critical issues to be addressed for $\mathrm{Si}$ anodes prior to their practical application. The large volume changes of $\mathrm{Si}$ anodes upon charging and discharging lead to the pulverization of Si particles and unstable solid-state electrochemical interphase (SEI) layers.

To help construct better SEI layers, besides using electrolyte additives, forming a coating on Si surfaces is a good approach. Metal oxides $\left(\mathrm{TiO}_{2},{ }^{2-5} \mathrm{Al}_{2} \mathrm{O}_{3},{ }^{6-8} \mathrm{Co}_{3} \mathrm{O}_{4},{ }^{9,10}\right.$ and $\mathrm{RuO}_{2},{ }^{11}$ etc. $)$ were used to coat $\mathrm{Si}$ particles or thin films. For example, Lotfabad et al. ${ }^{2}$ used an atomic layer deposition (ALD) to coat $\mathrm{TiO}_{2}$ on silicon nanowires; the obtained materials show better cyclic performance compared with the pristine Si nanowires. Metals (such as $\mathrm{Al},{ }^{12} \mathrm{Ag},{ }^{13} \mathrm{Cu},{ }^{14-17}$ and $\mathrm{Ni}^{17}$ ) have also been coated on $\mathrm{Si}$ surfaces to improve the cyclic performance of $\mathrm{Si}$ anodes. For example, Murugesan et al. ${ }^{15}$ synthesized Cu-coated Si particles by depositing copper on the a-Si:H particles using a polyol reduction method. Since the SEI layer on carbon is much more stable and carbon possesses a higher electrical conductivity, coating carbon on Si surfaces has been investigated intensively. ${ }^{18-21}$ For example, Wang et al. ${ }^{18}$ synthesized Si nanowires coated with carbon by thermal decomposition of ethylene. Coating conductive polymers is another choice. ${ }^{22-24}$ However, because of the large volume expansion of Si upon lithiation,

${ }^{a}$ Department of Mechanical Engineering, University of Wisconsin-Milwaukee, 3200 North Cramer Street, Milwaukee, Wisconsin 53211, USA. E-mail:jhchen@uwm.edu ${ }^{b}$ Global Technology \& Innovation, Power Solutions, Johnson Controls, 5757 North Green Bay Avenue, Milwaukee, Wisconsin 53209, USA

$\dagger$ Electronic supplementary information (ESI) available. See DOI: $10.1039 / \mathrm{c} 5 \mathrm{ra00764j}$ most of these coatings will crack, similar to what occurs to C-coated $\mathrm{SnO}_{2}$ observed by high-resolution transmission electron microscopy (HRTEM) ${ }^{25}$ Integration of coatings with the bulk Si can help prevent the coating layer from peeling off.

Here we report an Si anode with chemically bonded silicide surface that is expected to be more stable than a physically coated surface. To demonstrate our concept, nickel was coated on Si surfaces, followed by a heat-treatment to trigger Ni to react with the surface Si, forming a silicide coating layer. The nickel silicide is an electrochemically inactive intermetallic phase in lithium-ion batteries, ${ }^{26-29}$ but has not been deliberately designed as a protecting surface of Si anodes until now. The nickel silicide coating layer can act as a "skin" on Si and is expected to improve the cyclic performance of Si anodes. Compared with the pristine Si losing $51.8 \%$ of the reversible capacity after 50 cycles, the nickel silicide-coated Si shows significantly improved cyclic performance, for example, retaining $84.8 \%$ of the reversible capacity for a $6 \mathrm{~nm}$ nickel silicidecoated Si anode.

Experimental details are shown in the ESI. $\dagger$ In brief, to obtain the $\mathrm{NiSi}_{x}$-coated $\mathrm{Si}$, as shown in Fig. $1 \mathrm{a}$, Ni was coated on

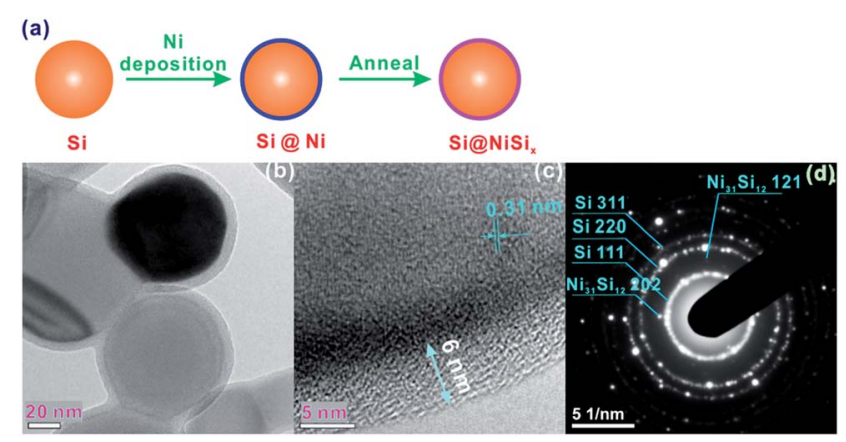

Fig. 1 (a) Schematic illustration of coating $\mathrm{NiSi}_{x}$ on the surface of $\mathrm{Si}$ nanoparticles, in which the Si was coated with Ni by sputtering, followed by annealing to allow the $\mathrm{Ni}$ to react with the $\mathrm{Si}$, forming the $\mathrm{NiSi}_{x}$ surface coating, (b) TEM image, (c) HRTEM image, and (d) SAED patterns of $\mathrm{Si} @ 6 \mathrm{~nm} \mathrm{NiSi}$. 
the surface of Si by sputtering, followed by annealing at $800{ }^{\circ} \mathrm{C}$; the sputtered $\mathrm{Ni}$ reacted with the surface $\mathrm{Si}$, forming the $\mathrm{NiSi}_{x}$ coating layer. The morphology of Si did not change after coating with $\mathrm{NiSi}_{x}$ as indicated by the scanning electron microscopy (SEM) images (Fig. S1 $\dagger$ ), nor did its bulk structure as evidenced from the X-ray diffraction (XRD) pattern of the $\mathrm{NiSi}_{x}$-coated $\mathrm{Si}$ that shows only Si diffraction peaks (Fig. S2 $\dagger$ ). No oxides were detected, which suggests that the oxygen content, if present, is lower than the detection limit of the instrument. However, the $\mathrm{NiSi}_{x}$ coating layer can be identified by transmission electron microscopy (TEM) and high-resolution TEM (HRTEM) images of the as-prepared $\mathrm{NiSi}_{x}$-coated $\mathrm{Si}$, as shown in Fig. $1 \mathrm{~b}$ and $\mathrm{c}$. The Si particles in sample Si@6 nm NiSi $\mathrm{n}_{x}$ were uniformly coated with a coating layer of approximately $6 \mathrm{~nm}$ in thickness. Note that while the sputtering Ni vapour may deposit on the underlayer Si particles due to the high vacuum, not all of the $\mathrm{Si}$ particles were coated by the exact $6 \mathrm{~nm}$ of $\mathrm{NiSi}_{x}$; some of the $\mathrm{Si}$ particles were observed with a $c a .1 \mathrm{~nm}$ coating layer as suggested in Fig. S3. $\uparrow$ Theoretically, the thickness of the coated Ni for sample Si@6 nm NiSi ${ }_{x}$ ranges from 3-6 nm because each $\mathrm{Si}$ particle has the chance to be coated twice of $3 \mathrm{~nm}$ Ni. However, as a matter of the fact, the Si particles located below the surface have less chance to be coated. Although a uniform $\mathrm{NiSi}_{x}$ coating is desirable to achieve the best protection for $\mathrm{Si}$, the nonuniform coating layer does not compromise our main purpose in this study, namely, to demonstrate the function of the $\mathrm{NiSi}_{x}$.

The $d$-spacing of $0.31 \mathrm{~nm}$ shown in Fig. 1c corresponds to the $\{111\}$ diffraction planes. Because of the poor crystallinity of the coating layer, it is not possible to discern its crystallographics from HRTEM; however, we can identify the $\{202\}$ and $\{121\}$ diffraction planes of $\mathrm{Ni}_{31} \mathrm{Si}_{12}$ from the selected area electron diffraction (SAED) pattern (Fig. 1c). The energy dispersive X-ray spectroscopy (EDS) mapping indicates the uniform Ni distribution along with Si (Fig. 2a-c), and the EDS line scan confirms the uniform coating (Fig. 2d). Note that we did not observe an elevated Ni content on the edge of Si particle in Fig. 2d, which is likely due to the fact that $\mathrm{Ni}$ on the bottom side of Si surface contributes to the EDS signal since the electron beam can reach 1-3 $\mu \mathrm{m}$ in depth during EDS analysis operated at $10 \mathrm{kV}$ and

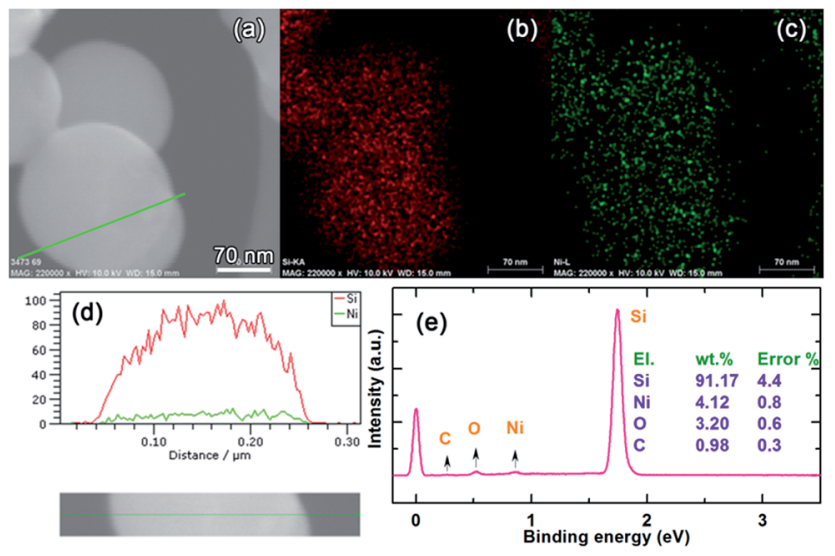

Fig. 2 (a) SEM image of Sia $6 \mathrm{~nm} \mathrm{NiSi}$ and its corresponding EDS analysis: elemental mapping of (b) $\mathrm{Si}-\mathrm{K} \alpha$, and (c) $\mathrm{Ni}-\mathrm{L}$, (d) line scan of the particle shown in (a), and (e) elemental composition analysis.

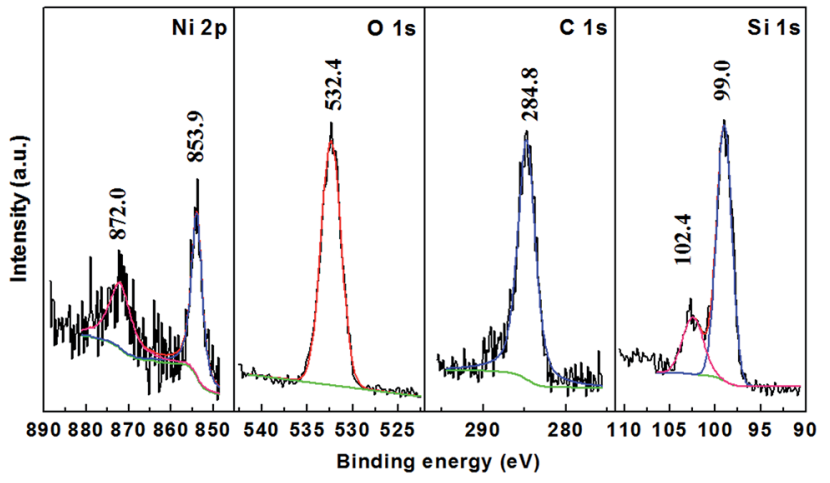

Fig. 3 XPS spectra of Si@6 $\mathrm{nm} \mathrm{NiSi}$, where the peaks were corrected by $\mathrm{C} 1 \mathrm{~s}$ at $284.8 \mathrm{eV}$.

$15 \mathrm{~mA}$. The Ni content in the $\mathrm{NiSi}_{x}$-coated $\mathrm{Si}$ is $c a .4 .12 \mathrm{wt} \%$ as suggested by the EDS analysis (Fig. 2e).

Sample Si@6 nm NiSi , for example, was characterized by X-ray photoelectron spectroscopy (XPS) as shown in Fig. 3. The peak centred at $99.9 \mathrm{eV}$ is ascribed to $\mathrm{Si}$ in the form of elemental Si and silicide, since their binding energies are too close to be separated. The shoulder peak at $102.4 \mathrm{eV}$ is associated with the surface silicon oxide because $\mathrm{Si}$ is prone to oxidation on the surface. The binding energy of the $\mathrm{Ni} 2 \mathrm{p}_{2 / 3}$ peak is centred at $853.9 \mathrm{eV}$, higher than the value belonging to elemental $\mathrm{Ni}(852.7 \mathrm{eV})$, but close to those of $\mathrm{Ni}_{3} \mathrm{Si}(852.8 \mathrm{eV}), \mathrm{Ni}_{31} \mathrm{Si}_{12}(853.0 \mathrm{eV}), \mathrm{Ni}_{2} \mathrm{Si}(853.4 \mathrm{eV})$, and NiSi $(853.9 \mathrm{eV}) .{ }^{29,30}$ This confirms that Ni exists in the form of silicides instead of elemental Ni. No NiO was detected as the O $1 \mathrm{~s}$ peak of $\mathrm{NiO}$ is located at $320 \mathrm{eV}$, lower than the observed symmetrical peak at $532.4 \mathrm{eV}$ for $\mathrm{O} 1 \mathrm{~s}$ in our sample. The $\mathrm{O} 1 \mathrm{~s}$ peak was ascribed to oxygen in a form of $\mathrm{SiO}_{x}$ because silicon oxide was detected as indicated by the Si 2p peak (102.4 eV).

The initial discharge capacity of pristine $\mathrm{Si}$ is 2881.3 $\mathrm{mA} \mathrm{h} \mathrm{g}{ }^{-1}$ at a current density of $120 \mathrm{~mA} \mathrm{~g}^{-1}$ with an initial Coulombic efficiency (CE) of $90.4 \%$ (Fig. 4a). After 50 cycles at the current density of $1200 \mathrm{~mA} \mathrm{~g}^{-1}$, its capacity was 882.8 $\mathrm{mA} \mathrm{h} \mathrm{g}^{-1}, 48.2 \%$ of its reversible capacity of $1832.6 \mathrm{~mA} \mathrm{~h} \mathrm{~g}^{-1}$ at the third cycle. In contrast, the $\mathrm{NiSi}_{x}$ coated samples delivered initial capacities of 2214.0, 1985.7, and $2213.4 \mathrm{~mA} \mathrm{~h} \mathrm{~g}^{-1}$ with initial CEs of $89.4 \%, 88.8 \%$, and $89.4 \%$ for 1,4 , and $6 \mathrm{~nm}$ coating layers, respectively. This means that the introduction of the $\mathrm{NiSi}_{x}$ coating layer decreased the capacity of the $\mathrm{Si}$ anode, e.g., by ca. $23 \%$ for sample Si@6 $\mathrm{nm} \mathrm{NiSi}$ (Fig. 4b), which suggested the existence of the $\mathrm{NiSi}_{x}$ coating layer because mixing $4.12 \mathrm{wt} \%$ of Ni will not decrease the capacity of the Si anode by $23 \%$, whereas the increased polarization by the $\mathrm{NiSi}_{x}$ will. In other words, it is more difficult for $\mathrm{Li}^{+}$to cross the $\mathrm{NiSi}_{x}$ coating layer compared with a conventional SEI layer. Despite the decreased initial capacity, forming a $\mathrm{NiSi}_{x}$ coating layer significantly enhanced the cyclic performance of the Si anode. As shown in Fig. 4a, the capacities at the 50th cycle are 1237.4, 1123.1, and $1256.0 \mathrm{~mA} \mathrm{~h} \mathrm{~g}{ }^{-1}, 72.3 \%, 74.9 \%$, and $84.8 \%$ of the capacity at the $3 \mathrm{rd}$ cycle at $1200 \mathrm{~mA} \mathrm{~g}^{-1}$ for samples Si@1 nm $\mathrm{NiSi}_{x}, \mathrm{Si} @ \mathrm{~nm} \mathrm{NiSi} x$, Si@6 nm NiSi ${ }_{x}$, respectively.

As a comparison, we prepared a $6 \mathrm{~nm}$ Ni-coated Si without the subsequent heat-treatment; the as-obtained Si@Ni 

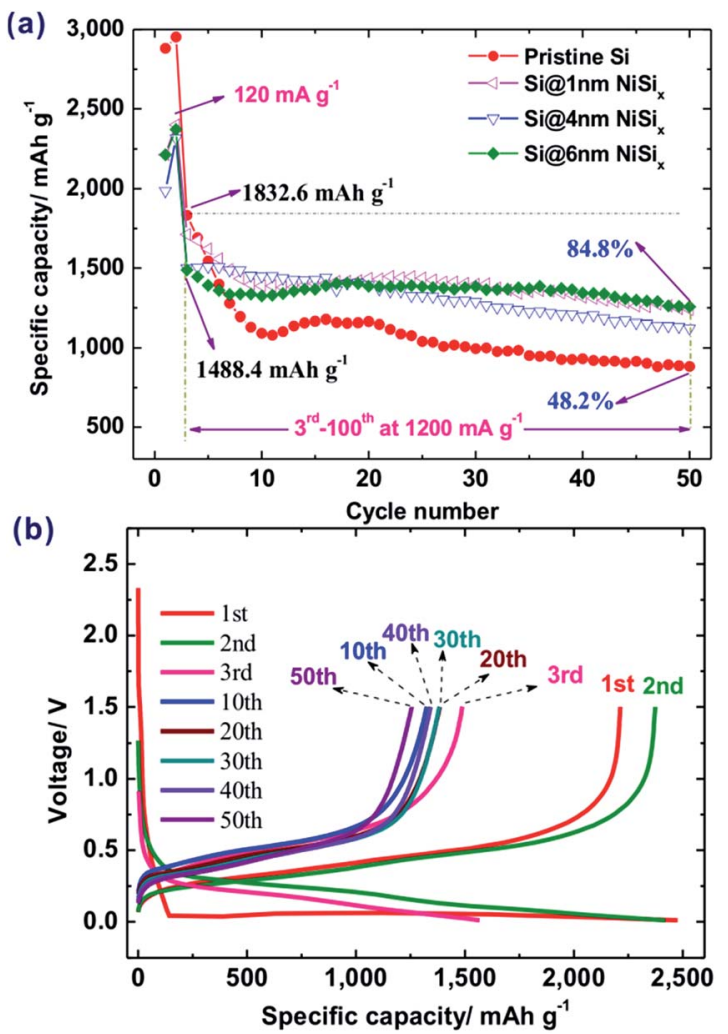

Fig. 4 (a) Cyclic performance of pristine $\mathrm{Si}$ and $\mathrm{NiSi}_{x}$-coated Si with various coating thicknesses, and (b) charge/discharge profiles of sample Si@6 nm NiSi

delivered a capacity of $3187.6 \mathrm{~mA} \mathrm{~h} \mathrm{~g}^{-1}$ at $120 \mathrm{~mA} \mathrm{~g}^{-1}$, and retained $51.2 \%$ capacity at the $50^{\text {th }}$ cycle at $1200 \mathrm{~mA} \mathrm{~g}^{-1}$ (Fig. S4 $\dagger$ ). As a result, while physically coating Ni slightly improved the capacity retention from $48.2 \%$ to $51.2 \%$, the chemically bonded silicide surface is much more effective for protecting the Si during cycling, namely, resulting in up to $84.8 \%$ of the capacity retention. Note that the Si@Ni possesses a higher capacity than the pristine $\mathrm{Si}$ and the silicide-coated $\mathrm{Si}$, which is associated with the fact that Ni metal helps improve the electrical conductivity.

Pure Si usually possesses very poor cyclic performance..$^{13,31,32}$ For example, Yu et $a l .{ }^{13}$ reported a commercial nanosized $\mathrm{Si}$ showing a capacity of $c a .3700 \mathrm{~mA} \mathrm{~h} \mathrm{~g}{ }^{-1}$ while decaying to almost zero within 50 cycles. Forming surface coatings on $\mathrm{Si}$ was reported to improve the cyclic performance of the Si. For example, Murugesan et al. ${ }^{15}$ synthesized Cu-coated Si particles by depositing copper on the a-Si:H particles by a polyolmediated reduction of copper acetate, showing a capacity of ca. $600 \mathrm{~mA} \mathrm{~h} \mathrm{~g}{ }^{-1}$ with enhanced cyclic performance. Chen et al. ${ }^{14,21}$ prepared C-coated and $\mathrm{Cu}$-coated Si nanowire anodes, retaining $75.0 \%$ and $86.3 \%$, respectively, of their initial capacities after 15 cycles at $0.05 \mathrm{C}$ rate; in contrast, the pristine $\mathrm{Si}$ nanowire anode retained $63.7 \%$ of its initial capacity. Considering that very good coating layers were achieved, ${ }^{14}$ the capacity decay of these coated Si anodes is possibly due to the coating layer breaking and peeling off from the surfaces of the $\mathrm{Si}$ nanowires or nanoparticles. As a matter of fact, a broken $\mathrm{C}$ (a)

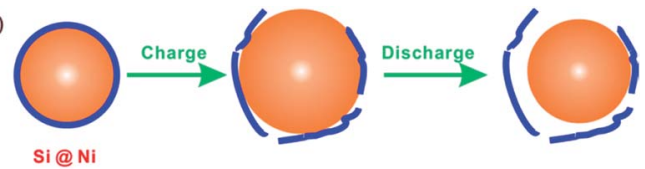

(b)

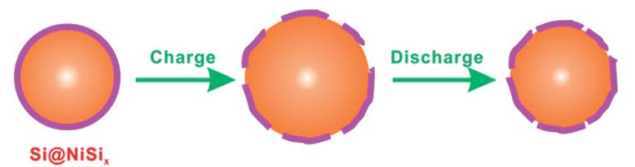

Fig. 5 Schematic illustrations of (a) failure mechanism of the conventional coating method, taking $\mathrm{Ni}$-coated $\mathrm{Si}$ as an example, and (b) the mechanism for the improved cyclic performance by the formation of the skin-like $\mathrm{NiSi}_{x}$ on the surface of $\mathrm{Si}$.

coating layer on the $\mathrm{SnO}_{2}$ surface was observed by an in situ TEM. ${ }^{33}$ As shown in Fig. 5a, taking the Ni-coated Si particle as an example, the coating layer will gradually form cracks and lose electrochemical contact with Si because of the large volume change of $\mathrm{Si}$ upon the repeated lithiation/delithiation. Compared with such a physical coating Ni layer serving as a "jacket" layer, our $\mathrm{NiSi}_{x}$ coating layer was formed by a reaction of the $\mathrm{Si}$ surface with the coated $\mathrm{Ni}$; consequently, the asobtained chemical coating layer acts as a "skin" layer. When the $\mathrm{NiSi}_{x}$-coated $\mathrm{Si}$ is charged, it may expand and crack somehow, but it will not peel off and lose contact with $\mathrm{Si}$ as shown in Fig. 5b.

Fig. S5 $\uparrow$ shows SEM images of the Si@6 nm NiSi $i_{x}$ electrode after 50 cycles; no cracks were observed on the particles, which may be due to the Si particle size smaller than $150 \mathrm{~nm}$, a critical size below which Si would not crack upon lithiation. ${ }^{34}$ In addition, the SEI layer on the surface of the Si particles may disturb the observation of the nickel silicide coating layer. However, we still can find that the $\mathrm{Ni}$ is well distributed on the surface of the Si particle by EDS mapping (Fig. S6 $\dagger$ ). Note that some big cracks were observed on the electrode (not on the Si particles; Fig. S5 †), which can explain why the silicide-coated $\mathrm{Si}$ anode still show decay. As a matter of fact, coating an active or inactive layer on the Si particle cannot reduce the volume change of Si upon lithiation, namely, formation of $\mathrm{Li}_{3.75} \mathrm{Si}$ will anyway lead to the volume expansion of Si up to $\sim 300 \%$. The strain between the particles due to the repeated expansion and contraction of the Si upon lithiation/delithiation eventually resulted in the cracks on the electrode. Nevertheless, the formation of the silicide coating layer did improve the cyclic performance of the $\mathrm{Si}$ anode, as discussed above, because the stable chemically bonded silicide coating layer can prevent the SEI layer from growing upon cycling.

Because sample Si@6 nm NiSi $x_{x}$ showed the best cyclic performance among the three $\mathrm{NiSi}_{x}$ coated samples, we took this sample as an example to investigate the mechanism of the improved cyclic performance. Fig. 6a shows CV curves of sample Si@6 $\mathrm{nm} \mathrm{NiSi}_{x}$, recorded at a scan rate of $0.05 \mathrm{mV} \mathrm{s}^{-1}$. During the initial cathodic scan, a current peak emerged at $0.19 \mathrm{~V}$, followed by another developmental peak below $10 \mathrm{mV}$, corresponding with lithiation of $\mathrm{Si}$ to various $\mathrm{Li}_{x} \mathrm{Si}$ phases. When potentials were swept anodically, there were two peaks at 

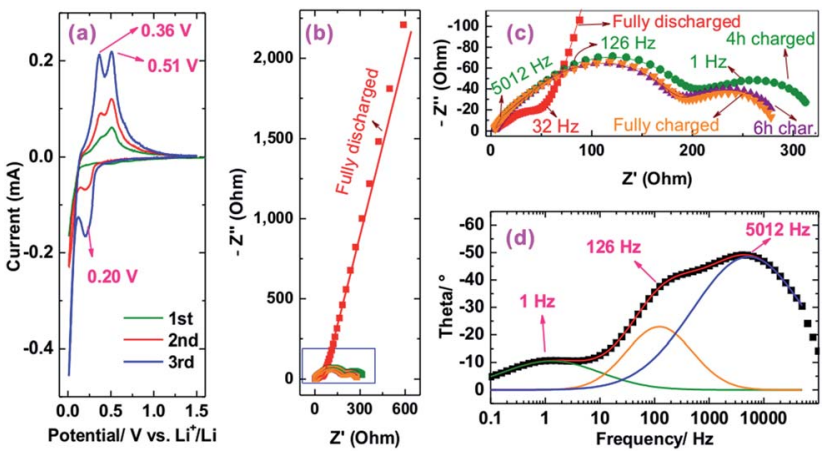

Fig. 6 (a) CV curves, (b and c) Nyquist plots at various states of charge, in which discrete points and solid lines represent the experimental data and the fitting results, and (d) Bode plot (discrete points) and their peak fitting results (solid lines). Note that the three highest-frequency points were removed during fitting because they are not very stable: including the three points will increase the fitting error significantly.

0.36 and $0.51 \mathrm{~V}$ due to the delithiation of the $\mathrm{Li}_{x} \mathrm{Si}$. The $\mathrm{CV}$ behaviour is very similar to our previously reported $\mathrm{Si} / \mathrm{Ni}$ composite. $^{29}$ Note also that the gradual development of cathodic and anodic peaks was commonly observed in CV curves of $\mathrm{Si}$ anodes, ${ }^{35-37}$ which is due to the gradual activation of $\mathrm{Si}$.

Fig. $6 \mathrm{~b}$ and $\mathrm{c}$ shows the electrochemical impedance spectroscopy (EIS) Nyquist plots of the $\mathrm{NiSi}_{x}$-coated $\mathrm{Si}$ anode. To reach a fully charged state, the anode was charged to $1.5 \mathrm{~V}$ and maintained at $1.5 \mathrm{~V}$ for $1 \mathrm{~h}$. After allowing the anode to rest for $1 \mathrm{~h}$, the anode was measured by EIS; its Nyquist plot exhibits a semicircle at the high frequency zone, followed by an inclined line after $c a .32 \mathrm{~Hz}$. The semicircle represents only the resistance of the SEI layer without charge transfer resistance because the potential of the anode is $1.461 \mathrm{~V}$, far away from the lithiation/delithiation potentials as indicated by the $\mathrm{CV}$ (Fig. 6a). The inclined line should be related to the diffusion of Li ions in the SEI layer instead of in the bulk of Si particles. This is in good agreement with our recent results on a $\mathrm{Si} / \mathrm{Ni}$ composite $^{29}$ and a Si flower anode. ${ }^{38}$

The $\mathrm{NiSi}_{x}$ coated $\mathrm{Si}$ anode was subsequently charged at $240 \mathrm{~mA} \mathrm{~g}^{-1}(\mathrm{C} / 10)$ for various durations to obtain its charge transfer resistance. After charging, apparently, there are two semicircles in the Nyquist plots (Fig. 6c); however, when we analysed the Bode plot, taking the $4 \mathrm{~h}$ charged state as an example, we found three peaks located at ca. 5012, 126, and $1 \mathrm{~Hz}$ (Fig. 6d), which are associated with the SEI layer, the $\mathrm{NiSi}_{x}$ coating layer, and the charge transfer, respectively. We therefore used a three time-constant equivalent circuit (Fig. S7 $\dagger$ ) to fit the Nyquist plots and summarized the results in Table S1. $\dagger$ Considering the resistances are typically stable at or near a half charged state, ${ }^{38}$ we averaged the resistances obtained at the $4 \mathrm{~h}$ and $6 \mathrm{~h}$ charged states, which shows that the Ohmic (including electrolyte and contact resistances), SEI layer, $\mathrm{NiSi}_{x}$ coating layer, and charge transfer resistances are 3.0, 40.0, 150.3, and 115.2 Ohm, respectively.

Compared with our previous $\mathrm{Si} / \mathrm{Ni}$ composite with the resistances of the SEI layer and the charge transfer of 60.0 and 139.5 Ohm, respectively, ${ }^{29}$ the present $\mathrm{NiSi}_{x}$-coated $\mathrm{Si}$ showed an extra $\mathrm{NiSi}_{x}$ coating layer resistance $(150.3 \mathrm{Ohm})$. Note that the capacities at $1200 \mathrm{~mA} \mathrm{~g}^{-1}$ at the 3 rd cycles are $71.2 \%, 64.7 \%$, and $62.7 \%$ of the values obtained at $120 \mathrm{~mA} \mathrm{~g}^{-1}$ at the 2nd cycles for samples Si@1 nm NiSi, Si@4 nm NiSi $i_{x}$, and Si@6 nm $\mathrm{NiSi}_{x}$, respectively (Fig. 4a), which means that the rate capabilities of the $\mathrm{NiSi}_{x}$-coated $\mathrm{Si}$ anode decreased with the increasing coating thickness. Therefore, forming a thinner $\mathrm{NiSi}_{x}$ coating layer, e.g., by the ALD technique, may lead to less capacity loss while enhancing the cyclic performance of Si anodes. Although forming a $\mathrm{NiSi}_{x}$ coating layer may increase the resistance and decrease the capacity, it can significantly improve the cyclic performance. Because Si possesses a theoretical capacity of $3579 \mathrm{~mA} \mathrm{~h} \mathrm{~g}{ }^{-1}$, approximately ten times that of commercial graphite anodes, it is worth improving its cyclic performance at the cost of a decreasing capacity. As a result, the formation of the $\mathrm{NiSi}_{x}$ coating layer like we designed here offers a new approach to improve the cyclic performance of $\mathrm{Si}$ anodes.

In conclusion, $\mathrm{NiSi}_{x}$-coated $\mathrm{Si}$ was synthesized by sputtering $\mathrm{Ni}$ on the surface of Si particles, followed by annealing at $800{ }^{\circ} \mathrm{C}$. The sputtered Ni reacted with the surface of the $\mathrm{Si}$, forming a $\mathrm{NiSi}_{x}$ intermetallic coating layer. Compared with the pristine $\mathrm{Si}$ losing $51.8 \%$ of its reversible capacity within 50 cycles, the $\mathrm{NiSi}_{x}$-coated Si with a $6 \mathrm{~nm}$ coating layer retained $84.8 \%$ of its reversible capacity. The improved cyclic performance is related to strong binding of the skin-like $\mathrm{NiSi}_{x}$ to the Si surface due to the chemical bonding, in contrast to relatively weak binding for a physically coated layer on $\mathrm{Si}$.

\section{Acknowledgements}

Financial support for this work was provided by the U.S. Department of Energy (DE-EE0003208) and Johnson Controls, Inc. The SEM imaging was conducted at the UWM Bioscience Electron Microscope Facility, and TEM analyses were conducted in the UWM Physics HRTEM Laboratory. The authors thank Dr H. A. Owen, Dr S. E. Hardcastle and D. P. Robertson for their technical support with SEM, BET and Raman, and TEM analysis, respectively.

\section{Notes and references}

1 U. Kasavajjula, C. S. Wang and A. J. Appleby, J. Power Sources, 2007, 163, 1003-1039.

2 E. M. Lotfabad, P. Kalisvaart, K. Cui, A. Kohandehghan, M. Kupsta, B. Olsen and D. Mitlin, Phys. Chem. Chem. Phys., 2013, 15, 13646-13657.

3 B. J. Jeon and J. K. Lee, Electrochim. Acta, 2011, 56, 62616265.

4 B. E. Kim, S. E. Park, J. C. Lim and J. K. Lee, Phys. Scr., 2010, 139, 014021.

5 O. Park, J. I. Lee, M. J. Chun, J. T. Yeon, S. Yoo, S. Choi, N. S. Choi and S. Park, RSC Adv., 2013, 3, 2538-2542.

6 Y. He, X. Q. Yu, Y. H. Wang, H. Li and X. J. Huang, Adv. Mater., 2011, 23, 4938-4941.

7 H. T. Nguyen, M. R. Zamfir, L. D. Duong, Y. H. Lee, P. Bondavalli and D. Pribat, J. Mater. Chem., 2012, 22, 24618-24626. 
8 J. C. Li, X. C. Xiao, Y. T. Cheng and M. W. Verbrugge, J. Phys. Chem. Lett., 2013, 4, 3387-3391.

9 Y. M. Kang, S. M. Lee, M. S. Sung, G. J. Jeong, J. S. Kim and S. S. Kim, Electrochim. Acta, 2006, 52, 450-454.

10 Y. Hwa, W. S. Kim, B. C. Yu, S. H. Hong and H. J. Sohn, J. Phys. Chem. C, 2013, 117, 7013-7017.

11 H. Usui, Y. Kashiwa, T. Iida and H. Sakaguchi, J. Power Sources, 2010, 195, 3649-3654.

12 E. L. Memarzadeh, W. P. Kalisvaart, A. Kohandehghan, B. Zahiri, C. M. B. Holt and D. Mitlin, J. Mater. Chem., 2012, 22, 6655-6668.

13 Y. Yu, L. Gu, C. B. Zhu, S. Tsukimoto, P. A. van Aken and J. Maier, Adv. Mater., 2010, 22, 2247-2250.

14 H. X. Chen, Y. Xiao, L. Wang and Y. Yang, J. Power Sources, 2011, 196, 6657-6662.

15 S. Murugesan, J. T. Harris, B. A. Korgel and K. J. Stevenson, Chem. Mater., 2012, 24, 1306-1315.

16 V. A. Sethuraman, K. Kowolik and V. Srinivasan, J. Power Sources, 2011, 196, 393-398.

17 H. Usui, N. Uchida and H. Sakaguchi, J. Power Sources, 2011, 196, 10244-10248.

18 W. Wang, M. Tian, Y. J. Wei, S. H. Lee, Y. C. Lee and R. G. Yang, Nano Energy, 2013, 2, 943-950.

19 C. Y. Du, M. Chen, L. Wang and G. P. Yin, J. Mater. Chem., 2011, 21, 15692-15697.

20 S. H. Ng, J. Wang, D. Wexler, S. Y. Chew and H. K. Liu, J. Phys. Chem. C, 2007, 111, 11131-11138.

21 H. X. Chen, Z. X. Dong, Y. P. Fu and Y. Yang, J. Solid State Electrochem., 2010, 14, 1829-1834.

22 Y. Yao, N. Liu, M. T. McDowell, M. Pasta and Y. Cui, Energy Environ. Sci., 2012, 5, 7927-7930.

23 H. S. La, K. S. Park, K. S. Nahm, K. K. Jeong and Y. S. Lee, Colloids Surf., A, 2006, 272, 22-26.

24 A. A. Arie, W. Chang and J. K. Lee, J. Solid State Electrochem., 2010, 14, 51-56.
25 X. H. Liu and J. Y. Huang, Energy Environ. Sci., 2011, 4, 38443860.

26 M. S. Park, S. Rajendran, Y. M. Kang, K. S. Han, Y. S. Han and J. Y. Lee, J. Power Sources, 2006, 158, 650-653.

27 T. Kim, S. Park and S. M. Oh, Electrochem. Commun., 2006, 8, 1461-1467.

28 H. X. Chen, Q. B. Zhang, J. X. Wang, D. G. Xu, X. H. Li, Y. Yang and K. L. Zhang, J. Mater. Chem. A, 2014, 2, 84838490.

29 X. K. Huang, H. H. Pu, J. B. Chang, S. M. Cui, P. B. Hallac, J. W. Jiang, P. T. Hurley and J. H. Chen, ACS Appl. Mater. Interfaces, 2013, 5, 11965-11970.

30 Y. Cao, L. Nyborg and U. Jelvestam, Surf. Interface Anal., 2009, 41, 471-483.

31 H. M. Jeong, S. Y. Lee, W. H. Shin, J. H. Kwon, A. Shakoor, T. H. Hwang, S. Y. Kim, B. S. Kong, J. S. Seo, Y. M. Lee, J. K. Kang and J. W. Choi, RSC Adv., 2012, 2, 4311-4317.

32 X. S. Zhou, Y. X. Yin, L. J. Wan and Y. G. Guo, Chem. Commun., 2012, 48, 2198-2200.

33 L. Q. Zhang, X. H. Liu, Y. Liu, S. Huang, T. Zhu, L. J. Gui, S. X. Mao, Z. Z. Ye, C. M. Wang, J. P. Sullivan and J. Y. Huang, ACS Nano, 2011, 5, 4800-4809.

34 X. H. Liu, L. Zhong, S. Huang, S. X. Mao, T. Zhu and J. Y. Huang, ACS Nano, 2012, 6, 1522-1531.

35 C. K. Chan, H. L. Peng, G. Liu, K. McIlwrath, X. F. Zhang, R. A. Huggins and Y. Cui, Nat. Nanotechnol., 2008, 3, 31-35. 36 Y. Zhao, X. Z. Liu, H. Q. Li, T. Y. Zhai and H. S. Zhou, Chem. Commun., 2012, 48, 5079-5081.

37 T. Jiang, S. C. Zhang, X. P. Qiu, W. T. Zhu and L. Q. Chen, Electrochem. Commun., 2007, 9, 930-934.

38 X. Huang, J. Yang, S. Mao, J. Chang, P. B. Hallac, C. R. Fell, B. Metz, J. Jiang, P. T. Hurley and J. Chen, Adv. Mater., 2014, 26, 4326-4332. 